\title{
The Nature and Meaning of the Near-Death Experience for Patients and Critical Care Nurses
}

\author{
Linda L. Morris, Ph.D., RN, C \\ Nursing Education Consultants, Darien, IL \\ Kathleen Knafl, Ph.D., FAAN \\ Yale University, New Haven, CT
}

ABSTRACT: This study was designed to develop a conceptual framework for the near-death experience (NDE), reflecting its nature and meaning for the patient and the critical care nurse. The study used naturalistic inquiry to examine the question: What is the nature and meaning of an NDE and how has it influenced the individual's view of the self, the future, and feelings and beliefs about life and death? The NDE Scale (Greyson, 1983) was used with patients and semi-structured interview guides were used with both nurses and patients to explore the NDE from a comprehensive perspective. An NDE was defined as the report of "unusual" recollections associated with a period of unconsciousness during either serious illness or injury, or resuscitation from a cardiac or respiratory arrest. The sample included 12 patients who experienced an NDE and 19 nurses who cared for patients who experienced NDEs. This study highlighted the emotional aspects of the NDE. Patients described how the NDE transformed their lives and nurses reported how their experiences with patients changed them personally and professionally.

KEY WORDS: near-death experience (NDE); qualitative research; aftereffects; unconsciousness; spirituality; spiritual distress.

Linda L. Morris, Ph.D., RN, C, is the President of Nursing Education Consultants of Darien, IL. Kathleen Knafl, Ph.D., FAAN, is a professor in the doctoral program at the Yale University School of Nursing, where she is pursuing a program of research related to family response to childhood chronic illness. This paper is based on a presentation at the International Association for Near-Death Studies Annual Conference, Seattle Pacific University, July 27, 2001. Reprint requests should be addressed to Dr. Morris at 8305 Highpoint Circle, Suite A, Darien, IL 60561. 
Despite the abundance of writings in the lay press on the near-death experience (NDE) and related phenomena, it is a poorly understood event in the intensive care unit. One may wonder why there is such interest in a topic that is so difficult to explain. In the literature, the definition of what constitutes an NDE is unclear. Patients may be considered "near-death" as a result of several factors, such as cardiac or respiratory arrest, and severe shock or trauma. However, a common attribute of such states is a period of unconsciousness that is not the result of anesthesia. To the observer, these patients do not (or cannot) respond, but it is during this period of unconsciousness when some survivors have reported unusual recollections, some of which have been verified by others.

Many people claim that the NDE is "proof" of an existence beyond death because some survivors claim to have experienced "the hereafter." Other researchers claim that the NDE is merely the sensory manifestation of a dying brain (Blackmore, 1988, 1991) or produced by erratic electrical misfiring in the brain (Carr, 1982) or chemical imbalances (Jansen, 1990). Still others lie in the middle, convinced that there is something compelling in the stories of those who have experienced another dimension, but unable fully to understand it. Despite the wide range of skepticism and sometimes sensationalism, those who have had an NDE are, nonetheless, often changed by it. Their experiences also affect people who hear the stories of those who have had NDEs.

Although exact numbers cannot be known, many survivors of cardiac arrest have experienced an NDE; however, critical care personnel have inadequate knowledge to manage these patients. And it is clear that these patients need a supportive person to listen to their stories and understand their concerns (Garrison, 1989; James, 1994). It is estimated that 1,000 sudden cardiac deaths occur in the United States every day (Emergency Cardiac Care Committee and Subcommittees, 1992). Featherston defined sudden cardiac death as "an unexpected witnessed death of an apparently well person resulting from cardiac dysfunction and occurring within 1 hour of the onset of new symptoms" (1988, p. 242). Results of successful resuscitation in the hospital have not been systematically reported due to several factors; however, several informal sources list survival rates at 53 percent (C. McLane, personal communication, February, 1993), 60 percent (D. Knudsen, personal communication, May, 2000), or 67 percent (Morris and Fachet, 1992). Considering that these figures do not take into account the numerous factors involved, such as cause or lengths of survival, these 
numbers are quite similar. If these figures are representative, then a large number of persons each year are surviving clinical death.

\section{Literature Review}

Survivors of NDEs have significant psychosocial issues to resolve after the acute event. One of us (L.L.M.) conducted a preliminary integrative review of the literature on survivors of cardiac arrest and myocardial infarction, concluding that the major issues were linked to resolving the meaning and addressing the emotional sequelae. In other words, survivors of cardiac arrest and myocardial infarction, a large group of patients who experience NDEs, need the support of caregivers who are well-informed regarding their emotional needs.

The early literature on the NDE, through the early 1980s, described features associated with the experience itself, such as a light, a tunnel, and an out-of-body experience (OBE). The literature of the later $1980 \mathrm{~s}$ reported on the aftereffects of the experience. The integrative review of the literature included 13 studies that discussed the features associated with an NDE, only two of which (Greyson and Stevenson, 1980; Morse, Castillo, Venecia, Milstein, and Tyler, 1986) described examination of medical records as a method to confirm inclusion criteria. Eight of the studies used convenience sampling methods, two studies described a purposive sampling approach, and one study (Atwater, 1988) described a random selection of cases from the archives of the International Association for Near-Death Studies. The remainder of the studies did not describe the sampling method.

Two studies included interview of a secondary source such as a family member or physician to support the primary source. Twelve of the studies used a questionnaire, but reliability data were absent in all but two (Greyson, 1983; Ring, 1980).

Gender and ethnicity seemed to be factors in reporting NDEs. Stuart Twemlow and Glen Gabbard (1984-85) reported that 65 percent of their sample of 339 near-death experiencers were female, and that male respondents tended to have NDEs much more commonly as a result of accident or physical injury than did females, who more often had an NDE as a result of illness. With two exceptions, most authors did not report the ethnic composition of samples. Bruce Greyson and Ian Stevenson (1980) reported that all their subjects were Caucasian; and Kenneth Ring (1980) reported that 95 percent of his sample of 102 subjects were Caucasian and 5 percent were African-American. 


\section{NDE Features}

The features of the NDE have been a topic of inquiry since 1975, when the popular book Life After Life (Moody, 1975) was published. In this work, Raymond Moody first described the NDE after interviewing 150 persons resuscitated from cardiac arrest or who otherwise came close to death as a result of severe accident or injury. He found a consistent pattern of features, which later came to be known as the "core experience" (Ring, 1984), including the following features. There is an initial sensation of peace and serenity, while seeing the self as separate from the physical body (an out-of-body experience, or OBE). Upon leaving the body, all pain is gone. The disembodied self enters a tunnel or darkness, traveling at great speed and encountering a light at the end of the tunnel, which seems to radiate love. Others come to greet and welcome the person to his or her new environment. While in the light, the individual experiences a life review or panoramic memory, which is observed objectively, yet experienced with the original emotions. The person then reaches a border or limit. Some are given the choice to return, whereas for others the decision is made for them. Upon return to the body, the pain, if previously present, returns.

Numerous studies have been conducted since this landmark work, and most have had consistent findings. Three studies also provided a measurement tool to measure the depth of NDEs, based on the number of characteristics reported (Greyson, 1983, 1985; Ring, 1980). The most notable exception to the consistency in the literature was a study of experiencers in India, who were less likely to have OBEs and had a tendency to have residual marks on the body after the experience (Pasricha and Stevenson, 1986). Other notable exceptions were the reports of frightening or "hell-like" NDEs (Bush, 1994; Greyson and Bush, 1992; Rawlings, 1978, 1993; Ritchie, 1978). These experiences are not as well reported as the core experience.

\section{Limitations in the Studies of Features}

There were several limitations that were noted in the studies that reported the features of the NDE. First, the method of subject recruitment was often self-selection. In many cases, it was the subject's response to a notice in a magazine that qualified them for the study, whether or not they were truly "near death" at the time of the incident. Being near death is very subjective, especially in our common language. To say "I 
almost died" can mean anything from acute embarrassment to being in a "near-miss" accident to being hospitalized in intensive care as a result of trauma or disease. In most cases, the state of near-death was not described, nor was it corroborated.

Another limitation of these studies was the skewed sampling of gender and ethnicity. Participants tended to be Caucasian and women, and there seemed to be no effort to obtain a representative sample of men and women of varying ethnic backgrounds.

In addition, there was no description of the instruments, which were presumably interview guides. In qualitative research, the instruments of data collection provide the basis for understanding the nature of the interview. Without a description of the instruments, it was impossible to determine whether the interview protocols were appropriate for the research questions.

\section{Studies of Meaning and Aftereffects}

There were eight studies of meaning and aftereffects included in the integrative review of the literature. All of them used an interview or questionnaire method of obtaining data. All of the studies described a positive outcome of the NDE. Three studies described a decreased fear of death (Bauer, 1985; Grey, 1985; Noyes, 1980). Half of the studies found that the subjects had a calmer and more accepting attitude toward others and life in general. Other studies reported a strengthened belief in life after death, a renewed sense of purpose in life, or a re-evaluation of priorities (Bauer, 1985; Ring, 1984; Ring and Valarino, 1988). Taken together, these studies of the meaning and aftereffects of the NDE pointed toward a process of changed values and beliefs as a result of the experience. There was less concern with material things and more concern with relationships following the NDE. Another term that could describe this outcome was increased spirituality, which is defined as pertaining to the "spirit or soul as distinguished from the body or material matters" (Guralnik, 1980, p. 1373). This view coincided with an interesting concept analysis of spirituality (Haase, Britt, Coward, Leidy, and Penn, 1992), which found that the three outcomes of spirituality were a purpose and meaning in life, guidance of values and behavior, and self-transcendence, which reaches out beyond reality and allows the individual to rise above personal and material concerns. This description of spirituality fits well with the studies of meaning and aftereffects of NDEs. The present study was built on these studies of meaning and aftereffects. 


\section{Specific Aims of This Study}

The NDE is a very personal and individual experience that has great meaning to those who experience it. Critical care practitioners care for people at significant moments of crisis in their lives. They hear stories from their patients who have experienced NDEs. NDEs hold great meaning for the patients as well as the practitioners who care for these patients. Although the subjective experiences of the patients and the nurses regarding the NDE are described in this study, it was the degree to which people were changed and the way in which they were changed that is the major focus.

For this study, a near-death event was the condition that caused the patient to be near to death: for example, cardiac or respiratory arrest, severe shock, or trauma. The term NDE referred to the report of features associated with a period of unconsciousness due to a near-death event.

This research was designed to develop a conceptual framework for the near-death experience reflecting its meaning and significance for the patient and the nurse. The study used naturalistic inquiry to examine the question: What is the nature and meaning of a near-death experience and how has it influenced the individual's view of the self, the future, and feelings and beliefs about life and death? Specific aims that guided the collection of data included: (1) describing the experience of the patient surrounding the period of unconsciousness; (2) describing the nature and meaning that this experience holds for the patient, in terms of the individual's view of the self, the future, and relationships with others; (3) describing the experience of critical care nurses in caring for patients before, during, and after the period of unconsciousness, which was not linked to anesthesia; (4) describing the nature and meaning that this experience holds for the nurse, in terms of the nurse's view of the self, the future, and the caregiver role; and (5) comparing the responses of nurses and patients with regard to perception, meaning, and significance of these experiences.

One goal of this study was to address some of the shortcomings of previous research on the subject. Subjects were sought purposefully, rather than relying on self-selection as in many of the previous studies. Second, the state of near-death was specifically defined and subjects who met the criteria were included. Third, the state of near-death was verified in most instances. Fourth, there was an equal sampling of men and women, and a sample of ethnic diversity was purposively sought. Finally, the instruments used were clearly described. 


\section{Study Design and Methods}

This study used the qualitative approach of naturalistic inquiry (Lincoln and Guba, 1985), which is the process of exploring naturally occurring phenomena in order to gain understanding. For the purpose of this study, an NDE was defined as the report of "unusual recollections associated with a period of unconsciousness during either serious illness or injury, or during resuscitation from a cardiac or respiratory arrest." In order to enhance completeness of the topic and validity of the findings, triangulation of methods was used. This included the use of intensive interviewing in conjunction with a structured instrument, the Near-Death Experience Scale (Greyson, 1983), in order to elicit the perspectives of both patients and nurses. Credibility of the findings was enhanced by the use of multiple sites, multiple subjects, and multiple modes of data collection.

\section{Participants}

Participants were recruited from eight hospitals within the Chicago metropolitan area. Multiple sites were targeted to assure a diverse sample with regard to demographic characteristics, including ethnicity, gender, and socioeconomic status. The patient sample included 12 adults, age 18 and older, who had either survived and had recall of a cardiac or respiratory arrest, or who had survived a serious illness with a period of unconsciousness that was not linked to anesthesia. The nurse sample included 19 critical care nurses who had cared for at least one patient who had experienced an NDE. Thirty-five audiotaped interviews were conducted and transcribed verbatim. An additional group interview consisted of nurses' discussion at a continuing education program for nurses on NDEs that one of us (L.L.M.) led.

Patients. The patient sample included six men and six women. One subject who had no recall of the experience was used for comparative purposes. Patients were recruited from eight hospitals within the Chicago metropolitan area. The patients ranged in age from 24 to 73 years, with a mean of 48.1 years. The age of the men ranged from 32 to 73 years, and the age of the women ranged from 24 to 66 years. Six patients were married, four were divorced, and two were single. Ethnic background included eight Caucasian subjects, two AfricanAmerican, one Asian, and one Syrian. Religious affiliations included 
eight Protestants, two Christian, one Jewish, one Catholic, and one patient who did not identify a religious affiliation.

The events that precipitated the NDE included a combination of acute and serious health problems, as well as traumatic events. The serious health problems included septic shock, hypovolemic shock, diabetic coma, and hepatic coma. The acute events included cardiac arrest, ventricular fibrillation, respiratory arrest, respiratory distress, and ruptured ectopic pregnancy. The traumatic events included a bicycle accident in which one patient was hit by a truck, and a stab wound to the heart.

Nurses. The nurse sample included 19 critical care nurses. All of the nurses indicated that they had cared for patients who had an NDE. Their age ranged from 31 to 53 , with a mean of 43.6 years. Religious affiliations included 9 Catholics, 8 Protestants, and 2 who did not affiliate with any particular religion. Years of experience in nursing ranged from 3 to 26 , with a mean of 16.4 years.

\section{Procedure}

Six patients were interviewed within one month of their NDE and six patients were interviewed within two years of the experience. In order to examine the process of recovery from the event, three of the patients from the first group were interviewed a second time, four to six months after the event. For comparative purposes, one of us (L.L.M.) also used theoretical sampling for one interview in selecting a subject who experienced a near-death event but had no memory of the period of unconsciousness.

All 12 patients were asked to sign an informed consent agreement and were assured of the voluntary nature of the study. Arrangements were then made for a taped interview and completion of the NDE Scale.

In seven patients, the medical records were reviewed in order to provide background information so that potential confounding variables (such as drugs, length of arrest, and type of near-death event) could be identified. The records of the remaining patients were unavailable for review, most often because the patient was cared for at a nonparticipating hospital.

Patients and nurses were interviewed at a time and place of their choice. One of us (L.L.M.) conducted all interviews. The interview guides were used in a flexible manner, with the primary objective of encouraging all subjects to recount their experience in detail. 
Separate interview guides were developed and pilot tested for patients and for nurses. The patient interview guides were developed to explore the period of unconsciousness as well as the meaning and significance of the NDE. A follow-up interview guide was developed to determine whether participants' feelings and beliefs changed over time.

The nurse interview guide explored a variety of issues related to life and death and patients' thoughts and feelings surrounding resuscitation. Questions on the interview guides reflected the aims of the study, the literature, and our clinical experience.

For this study, the purpose in utilizing the Near-Death Experience Scale (Greyson, 1983) was to provide a foundation for the depth of the NDE itself. The NDE Scale was based on previous work (Noyes and Slymen, 1978-79; Ring, 1980) and was developed in order to provide a specific measure of depth of and NDE. The final NDE Scale of 16 items was derived from responses of 67 individuals describing 74 NDEs. Four item clusters were identified: cognitive, affective, paranormal, and transcendental. Crohnbach's alpha was .88 for the entire scale and ranged from .66 to .86 for each cluster. Test-retest reliabilities after four to six months were .92 for the entire scale and ranged from .79 to .95 for each cluster.

\section{Data Management and Analysis}

Each of the 35 interviews was transcribed verbatim, resulting in more than 900 pages of transcripts. Each line of text was analyzed for content and meaning and assigned an appropriate descriptive code, based on the aims of this research. Codes were then further reduced and grouped, first into major themes, and then into major category domains. Two categories of themes were short-term meaning and longterm meaning.

In order to verify consistency and reliability of coding, three transcripts were checked with a doctorally prepared colleague with expertise in qualitative technique. Coding two transcripts each, the initial reliability rate of the interviewer (L.L.M.) and the expert was 76 percent. In order to ensure completeness and reliability of coding, we reviewed all of the transcripts and recoded each one. This was a helpful exercise, in that we were able to correct several instances of codes that were too specific, and several additional codes were added. The expert was asked to code a third transcript, which was compared to that of the interviewer. The final percent agreement was 96 percent. 


\section{Ethical Considerations}

This study was approved by the Institutional Review Board (IRB) of the University of Illinois at Chicago and by each cooperating hospital. Each participant signed a consent form prior to the interview and completion of the NDE Scale. Participants were assured that their identities would be kept confidential and that no identifying information would be published in any reports resulting from this study.

A pilot study showed that there were some strong emotions elicited, including crying, from the interviews. We assured the participants that they were free not to answer any questions that made them uncomfortable, and that they were free to terminate or reschedule the interview at any time. However, none of the participants indicated that he or she wished to end the interview prematurely.

Confidentiality was assured by assigning each participant a code number. A master list of participants' names and code numbers was kept in a locked office in the event that a participant needed to be contacted for further information, or scheduled for a follow-up interview.

\section{Results}

Patients' Level of Consciousness

All 12 patient participants experienced a period of unconsciousness; however, in many cases, it was difficult to assess the duration of the unconsciousness because the documentation in the medical record often did not specifically identify level of consciousness. For seven of the 12 patients, the interviewer (L.L.M.) reviewed the records and corroborated the patient's account of the experience. The remaining five medical records were not available, most often because the patient was not recruited through a hospital.

\section{Patients' NDE Scale Scores}

Eleven patients completed the NDE Scale (Greyson, 1983), which was used to identify relative depth of the NDE. Determination of depth was made by an assessment of the number of features that were experienced during the NDE and the degree to which they were experienced.

The mean score of these 11 participants on the NDE Scale was 14.5 $(\mathrm{S} . \mathrm{D} .=6)$, with a range of 4 to 25 . The mean score on the Cognitive Component of the scale was 2.2 (S.D. $=2$ ), with a range of 1 to 6 ; the 
mean score on the Affective Component was 4.2 (S.D. $=2$ ), with a range of 0 to 8; the mean score on the Paranormal Component was 3.3 (S.D. $=$ 2 ), with a range of 0 to 8 ; and the mean score on the Transcendental Component was 4.8 (S.D. $=2$ ), with a range of 0 to 7 . These scores are comparable to those reported by Greyson (1983) on his index sample of near-death experiencers.

Cronbach's alpha was .72 for the entire NDE Scale, .47 for the Cognitive Component, .46 for the Affective Component, .78 for the Paranormal Component, and .49 for the Transcendental Component. These reliability scores were significantly lower than those reported by Greyson (1983), with the exception of that for the Paranormal Component. The comparatively low alphas in this sample reflect the small number of patients studied. Therefore, one must interpret our results with caution. Nonetheless, these results do indicate that there was wide variability in the NDEs of these patients, demonstrating that their experiences were quite diverse.

\section{Patient Interviews}

The experiences of the patients in this sample suggested that the NDE was a combination of physical, sensory, and emotional events. In general, the patients in this sample had similar experiences to those previously reported in the literature, which also described NDEs as a combination of sights, sounds, emotions, and sensations.

Men and women equally experienced a border (or point of no return), an OBE in which they felt separated from their physical body, and the sense that they were dying or dead. Eleven of the 12 subjects experienced the presence of deceased relatives and voices during their NDE. Men were more likely to experience a light and a tunnel. Women were more likely to experience presences and colors during their NDE. Only one man experienced extrasensory perception (ESP) during his NDE; however, three women experienced ESP as an aftereffect of their NDE.

The number of features that each patient experienced was compared to his or her score on the NDE scale, and no significant correlation was found ( $\mathrm{r}=.04$ ). In other words, a patient who experienced a large number of features with the NDE (such as a light or a tunnel) did not also have a high score on the NDE scale. The reason for this lack of correlation is unclear. One might expect that a large number of features would correlate with a higher score on the NDE scale; however, this was not the case. One possible explanation may be that the subjects 
did not correctly complete the instrument. Although it appears to be self-explanatory, the subjects may have been confused about the features and terms identified in the scale. In this study, instruments were reviewed and analyzed after interviews were completed, so it was not possible to ask patients to explain their responses on the NDE Scale. Had they been reviewed and discussed during the interview, the correlation might have been higher.

The features reported in this sample correspond directly with those reported in the literature and reflect the features described above in the core experience. In all cases, the patients reported that they believed that they had been changed as a result of having had the experience. We present direct quotes from participants in the following sections to illustrate the degree to which they were changed.

\section{Meaning and Significance of the NDE for Patients}

Figure 1 depicts a model illustrating the meaning of the NDE and the significance that the patients attributed to it. Meaning of the NDE indicates the way in which the subject interpreted or explained the experience, or the features of the experience. Significance of the NDE indicates the priority that the NDE or its aftereffects assumed in the subject's life. The patients were sometimes not sure how to interpret the events of their NDE; however, the experience was often very emotional and personal for them.

As shown in the Fig. 1, the data support conceptualizing the meaning of the NDE as an awakening, both because of the depth of emotion and the resultant struggle to find meaning in the experience itself, as well as find meaning in their life's purpose. This awakening was the beginning of an exploration into new ways to understand the world.

\section{Patients' Search for Understanding}

Immediately after the NDE, the initial phase of this awakening was characterized by frustration. Patients reported that they realized that something very powerful had just happened to them; however, they did not know how to interpret it or what its meaning was. Participants reported that they were frustrated in the search not only for meaning of the experience, but also for the meaning of life in general. The theme of this initial phase was a search to find meaning in the NDE. Seven patients also reported that they believed that they had received a special favor from God, a sign, or a "second chance." They believed that 


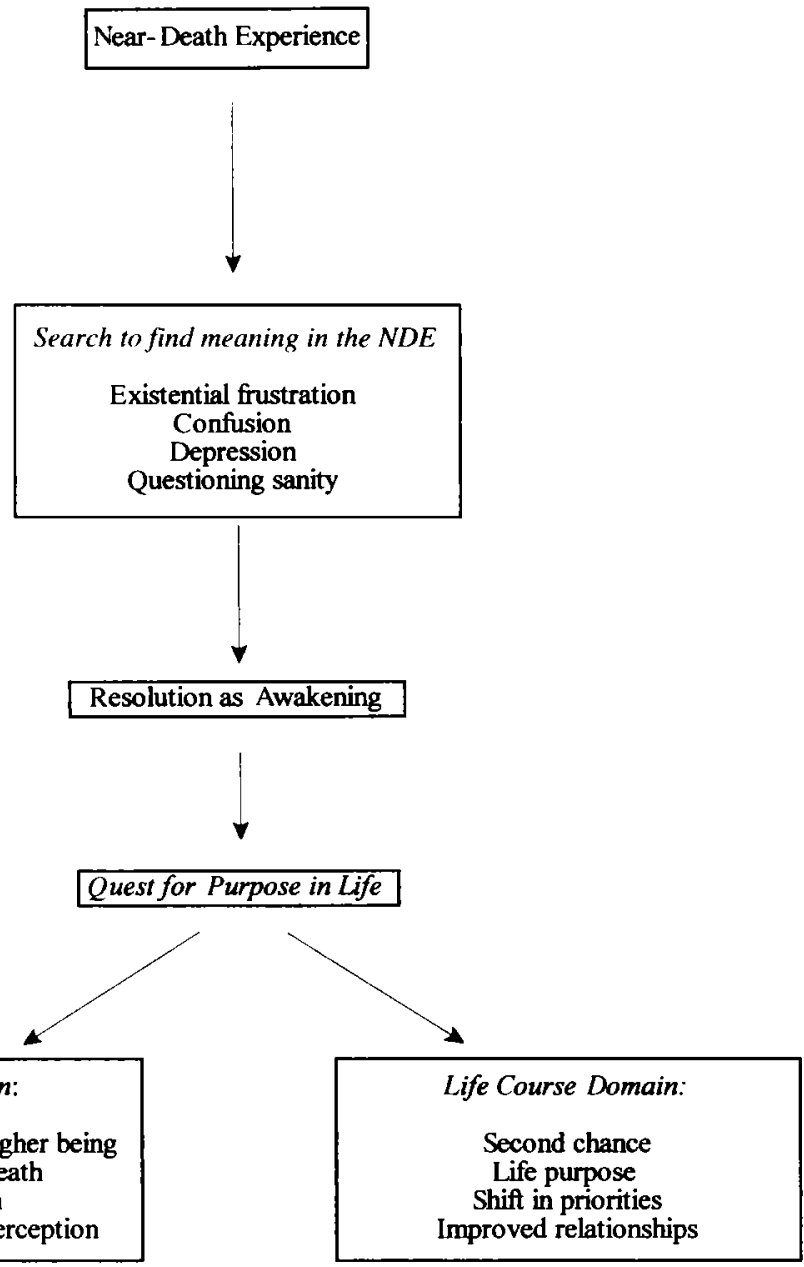

Fig. 1. Model of the Meaning and Significance of Patients' NDEs

they were chosen for a special purpose, and because of that, put some pressure on themselves to live their lives differently:

But I, I feel like I should be doing something better ... in terms of, you know, having a tremendous... I got a tremendous present, and how am I supposed to use it? 'Cause I'm supposed to use it; it's not just to get. So I'm uncomfortable not knowing how I'm supposed to use it. 
Characteristics of this phase of frustration were feelings of confusion, feelings of depression, and questions regarding their own sanity. Although all patients expressed some confusion following the NDE, their confusion manifested in different ways. Three patients were confused because they were unsure that the experience occurred, and others were unable to identify its meaning in their lives:

Well, at first I was very confused. I didn't understand this. It was very confusing to me. I couldn't-well, did I really experience this? Did this really happen? Or was this because of drugs, or, or all the other?... And I think-in some ways, in the beginning, maybe I was afraid to accept that maybe this was something that really was very spiritual and really had happened-and very confused by that.

Other common feelings after an NDE were depression and questioning their sanity. Three patients reported that they were depressed or were in some way troubled by the NDE. In one patient, this depression was related to delay in the progression of his physical recovery as well as the NDE. However, two other patients expressed a more "freefloating" sense of depression that they could not relate it to anything in particular:

The thing that troubles me most is that it's very hard to keep focused on what I would call the meaningful and the spiritual, the religious-I don't mean that in a formal sense - but the spiritual aspects of life. It's very hard to keep focused on it-and, that makes me unhappy. Second of all, I'm just in a generally lousy mood, which also makes me unhappy, because I know that it's just such a waste to be in a bad mood about stupid things. But I can't seem to shake either the bad mood or-it's like, it's like, circular. I don't know whether the bad mood's caused by my lack of focus on spiritual things, or my lack of focusing on spiritual things is caused by the bad mood. But clearly, they're related. So-I'm uncomfortable. I'm also uncomfortable with the notion that, you know, what I do has no societal value in my mind.

The NDE caused people to contemplate spiritual matters, and some even questioned their sanity. One patient seemed surprised and relieved to hear that the interviewer had heard several similar stories from other patients and said, "You mean, I don't have a screw loose, then?" More commonly, patients were afraid that others would view them as crazy.

Patients developed their own personal resolution to this "existential frustration," which then became a sort of awakening into a new way of looking at the world. 


\section{Patients' Beliefs About the NDE}

Overwhelmingly, patients reported that they believed that their NDE was confirmation that there is some sort of continued existence after what we know as death. The only patient who was not firmly convinced of the idea of life after death expressed these thoughts:

I don't see it as personally productive to think about whether there's life after death. Because the moment that you die, I believe that you think that there's life after death.... It doesn't matter if it's true, because it happened. So, who cares if what happens is that you're really in another level of existence-or you just think you are in the last moment that you can think. 'Cause either way, the last moment that you can think about it, it's a pleasant experience. Does it matter if it's really true?

\section{Telling Others About the NDE and Patients' Advice to Health Professionals}

Patients were asked about the reactions of others with whom they shared their experiences. Five of the patients reported that they learned to be cautious when sharing their experience with others, and shared them only with people who were likely to believe them.

When asked what advice patients would give to health professionals, some strong feelings were elicited. Patients reported that talking about the experience helped them. Patients reported that they believed that it was important for professionals to realize that patients may initially be confused about the experience, and that it was especially important not to minimize the experience by labeling it an hallucination. Whether or not the professional believes in the "reality" of the NDE, the patient participants felt the need for the professional to validate the experience and recognize it as one that was "genuine." When health professionals labeled the experience as an hallucination, it was interpreted as minimizing the experience, and patients no longer were comfortable talking about their experience to that person. Finally, the patients were very uncomfortable hearing information that was said in their presence, even though they were unconscious. They wanted health professionals to realize that, even though they may have appeared unconscious, they were often nonetheless able to see and hear what was going on around them. One subject overheard a nurse making a comment during her cardiac arrest, "Why don't they just let her die and put 
her out of her misery?" She wanted health professionals to understand how she felt:

I felt unworthy of life. I didn't like her. I thought, God, maybe I should die. Maybe I'm just--be a lot of trouble to these people, you know. I felt like maybe I was in the way.

Validation of the reality of the NDE by health professionals was important to those who experienced it.

\section{Patients' Quest for Purpose in Life}

As patients resolved their frustration, they entered a new phase we called the Quest for Purpose in Life. This phase included the more longterm aspects of meaning of the NDE. During this phase, subjects considered their NDE as a significant awakening into a new way of thinking. They became very interested in, indeed almost obsessed with, learning their purpose for being on this earth. This quest consisted of two primary domains: the Spiritual Domain and the Life Course Domain.

The Spiritual Domain revolved around the subject's relationship with a Higher Being. Patients described themselves as having a closer relationship with God, spending more time in prayer and development of their spiritual side, having a firmer belief in the existence of life after death, and having no fear of death. In addition, four subjects developed a new sense of intuition or extrasensory perception since their NDE. These patients reported that they were able to see events in the future, and they did not have this ability before their NDE.

The Life Course Domain reflected responses in which patients described the NDE as a turning point in terms of how they lived their lives and treated others. Their responses reflected the NDE as a "second chance" for them, an opportunity to clarify their life purpose, change priorities, and improve relationships with others. It is interesting to note that, although all of the patients knew that they had a purpose in their life, none of them could identify what their given purpose was, even though most were certain that it had to do with relationships with others:

I just had the generalized knowledge that I have a purpose, and-I'm supposed to try to figure out what the purpose is. ... I'm not uncomfortable with the notion that I might never know what the purpose is.

While considering the effect of the NDE on the patient, one may wonder whether it was the NDE itself or the state of being near to death that changed the lives of the subjects. To begin to explore this idea, 
one subject was interviewed who clearly had experienced a near-death event, specifically a near-drowning accident, but who had no memory whatsoever of the period of unconsciousness. She reported that she was grateful to be alive and that she did not suffer any permanent complications from the accident. She also considered herself a much nicer person, less self-centered and more expressive of appreciation. So this patient did have some changes in attitude as a result of the accident. However, the changes in attitude were due to her full recovery and gratefulness in being alive. The patients in this sample also expressed gratefulness, but the depth of their emotions went far beyond just being grateful and appreciative. Their attitudes, beliefs, and lives were transformed.

\section{Nurses' Accounts of Unusual Experiences Near Death}

Nineteen nurses were interviewed and asked about their experiences with patients who were near death or who had NDEs. The nurses' accounts showed that their own experiences were also a combination of physical, sensory, and emotional events. When telling their stories, it seemed that the nurses added more specific details of an unusual nature in order to describe the events more fully, even though they could not explain them. One nurse told the story of a patient who experienced an OBE during a cardiac arrest; however, she added an intriguing detail:

So she described this whole scene. And I says, "Well, where were you?" And she says, "I was, like, flying above everybody." And so, she described, typical of what you would see if you're doing, like, we'd do CPR on her. Now, I'm not there. I'm just describing what she's saying. And then she said something that was kinda funny. She said, "There was a penny on top of one of the cabinets; but you'd have to climb up to see." And I happened to mention this to another nurse who talks about things like I do. And she actually looked up there and found it.

Several nurses provided descriptions of patients for whom they had cared during a cardiac arrest, and the patients later related to them that, even though they were clearly unconscious, they remembered things that the nurses had said during the event. One nurse told the story of a patient who was aware of the conversations during her cardiac arrest:

And I was in doing her bath, and she said, "You were there yesterday." [Pause.] I was, like, yes-she was-you know, it was just like, "Do you remember anything?" She said, "You were up on the table with me, pounding on the chest, and I was above you." And she told me-I was wearing a skirt that day, because one of the doctors made a remark 
about don't wear dresses to work anymore.... And she just relayed the whole conversation that we'd had during this code, about my clothes.

\section{Physical Phenomena Experienced by Nurses}

The nurses' experiences were consistent with those that patients reported. Like the patients, nurses experienced a variety of sights, sounds, emotions, and sensations related to patients who were near death.

The sights described by nurses were most fascinating. Nurses reported seeing glows around their patients and visible presences at the bedsides of their patients. Five nurses observed a visible glow around their individual patients when they were near death. In four cases, this glow was blue in color. Another nurse in the pilot study mentioned a bluish-green glow around her patient just prior to a turning point in his recovery. She spoke of the eerie nature of the glow, which was clearly present despite the full light of day and was observed by another nurse. Other nurses also mentioned that they experienced a glow around their patients:

See... I don't wanna say I, like, actually saw an internal light bulb on. But you have the presence, or the feeling of really light and airy, without the breeze actually blowing.... It's almost like standing in the shadow of a light, of a light.... I would say a glow ... like a nightlight. ... It was around her ... but not, like, just her. It was, maybe her bed and ... her space, kind of thing. And then, it, like... it's almost like you don't want to believe it, 'cause nobody will believe you? So, you're almost denying it yourself.

Two nurses also described seeing "presences" at the bedsides of the patients while they provided care. One of them also described the blue glow around the patient and was able to confirm with the patient that there was a presence at her bedside:

There's someone in there. But we went in there, and she did, she had a blue glow all over her and it was-the room was filled with it. And she had, like her grandmother sitting next to her, holding her hand.... I don't know if it was her grandma, her mother, who, who it was. But she was just sitting there, holding her hand and-providing her comfort.... And I went up to her, and I said, "You know, you have someone sitting here taking care of you." And she looked at me, and she just shook her head yes.

Other nurses described visitations from patients for whom they had cared. Two nurses described visits by their patients while they, the nurses, were sleeping. Both nurses initially referred to these 
experiences as "a dream"; however, one of them explained that she was present in the patient's room, saw the events of his code, and even noted the time at which it had occurred. She later related the story to her colleagues who confirmed that everything had occurred exactly as she had seen it:

When I went home the next morning, I was very, very tired. At 1:15, I was lying in bed. I presume I was asleep. I was sleeping on my left side, and I felt a tap on my right shoulder-a very strong tap. And I opened my eyes, and there was this young man standing by my bed, with a very intense look on his face. He didn't say anything; he just looked at me. And he-I got the impression that he was in trouble again. I then closed my eyes, and-was immediately in his hospital room [snaps fingers] and saw him code, and saw-at that time ACLS [advanced cardiac life support]-this was back in the mid-80's and ACLS wasn't very big. None of the nurses have a very structured regime of what to do, was totally foreign. Nevertheless, I remembered what had happened to him, drug by drug by drug; minute by minute by minute-and the fact that he had come back. I woke up at 2 o'clock. I took my shower. I went into work, figured it was a dream, just a dream. And I sat there, and I said, "Hey, guys, I had the strangest dream. I dreamed that Mr. So-and-so in Room 14 coded, and that this and this and this were done." And they just sat there.... They just looked at me in stunned silence, and told me that this man had indeed coded at 1:15 in the afternoon, and that everything that I had told them was exactly what had happened to him.

Two nurses had visitations during their own personal crises while they were patients themselves. These nurses described "angels" who were sent to comfort them during their own hospitalization. One nurse, after suffering her own cardiac arrest, being pronounced dead, and facing surgery the next morning, told the story of a woman with whom she talked and who gave her reassurance that she would be fine:

And I was walking down the hall, and this-this little old lady was sitting in a chair in her room, and I could see her through the door. And she kind of beckoned me in. So I came in to talk to her. And she had, you know, little statues of Mary and Jesus and little holy cards around.... And it was mostly me talking ...talking about, you know, my surgery in the morning.... She just said, you know, "Jesus will take care of you. You'll be fine. Don't worry about anything." And, I just felt ... very calm. I felt absolutely reassured.... Several days after this experience, when I started to recover more, one of the nurses was walking me down the hall... and we walked past the room where this little old lady was, and she was on a ventilator. And I could see her face; I knew it was her... I was sure it was the same room. I'm looking, but it was her face; I knew it was-the same lady. And I said, "Oh, what happened to her?" You know, I was really shocked and distressed. And 
they said, "Well, what do you mean?" I said, "Well, you know, I'd been talking to her before my surgery, and now she's on a ventilator." And the nurse said, "No, you weren't talking to her before your surgery.". . And they said, "No, she was in a coma when she came in. She's been on a ventilator since she's been here. You didn't talk to her."

Nurses reported numerous other unusual experiences associated with patients who were near death. Two nurses spoke about hearing sounds in patients' rooms. One nurse heard sounds in the closet of her patient's room, which disappeared when she opened the closet door to check. Another nurse heard a noise in a patient's room down the hallway, which also disappeared when she checked the room.

Another tangible phenomenon reported by two nurses in this sample and one nurse in the pilot study was the presence of "cold spots" in the rooms. These nurses emphasized that these phenomena were not created by explainable causes, such as an open window. In both cases, the presence of these cold spots was corroborated by other nurses on the unit:

And I'd be, like, near these rooms, and I'd hear a noise or somethingand think-I remember thinking, oh, maybe a patient got up and lost their way to the bathroom or something... you know, like the first two or three times that it happened, you know?... And I'd go in there, and there would be no one there... I'd shine the light around, but as I passed, like-like, in between the bed, it would be, like, all of a sudden I'd walk, seriously, into a meat locker. It would be that cold-just in a spot-not the whole room... I'd walk into a certain place, and it would be really, really cold ... and other nurses...'cause I know we talked about it, and other nurses ... had said that they had felt the same thing.

\section{Meaning and Significance of the NDE for Nurses}

Figure 2 depicts a model of the meaning and significance that nurses attributed to NDEs of their patients. The NDE was a personal awakening for the nurses as well as for the patients. For many nurses, this was described as the first experience that opened the door of their scientific thinking into a realm beyond what they knew as reality.

As a result of their experiences with patients who reported NDEs and other unusual events, nurses struggled to explain in logical terms what had happened. One nurse expressed her awakening this way:

I--up to that point, I thought-very clinically. I didn't put any emotion into it.... And it was the first time I ever doubted physical medicine and started believing, maybe there was something else out theresomething, some other force that we can't measure. 


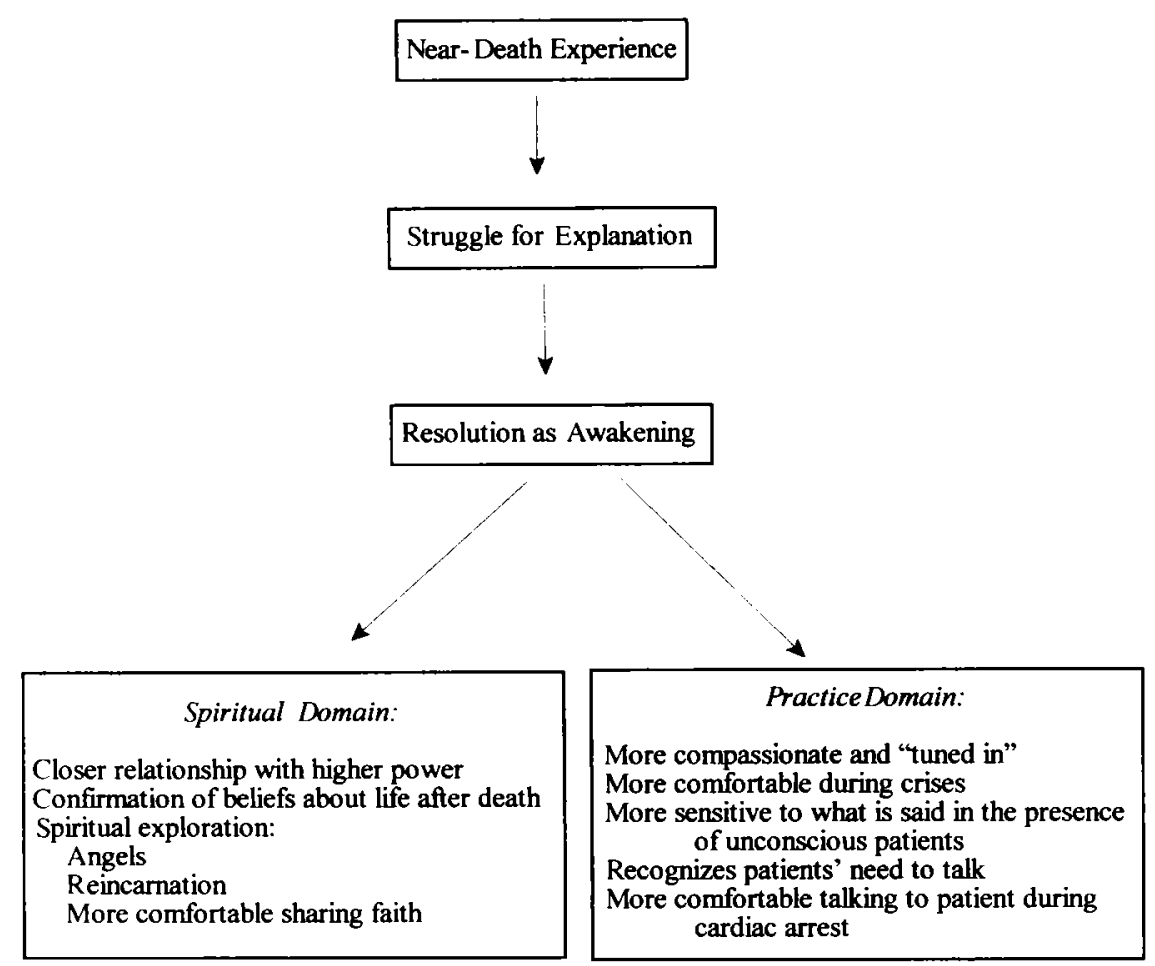

Fig. 2. Model of Nurses' Experiences

There were two primary domains regarding the meaning and significance of the experience described by the nurses: a Spiritual Domain and a Practice Domain. The spiritual domain encompassed their beliefs about God, faith, and life after death. The practice domain described how they incorporated their newfound beliefs and their experiences with NDEs into their role as a nurse.

Spiritual Domain. The Spiritual Domain reflected ideas that were deeply felt. Three nurses said that they felt a closer relationship with God as a result of their experiences. One former critical care nurse, now a psychiatric nurse, referred to herself as a "channel of God," which helped her better deal with her addicted patients:

I feel like I'm a channel of God, through me to get into that piece of their soul, and to cut through their crap-for them to, to be able to be more vulnerable, or to be able to deal with hard things-and to do 
what they need to do to get better and to be happy... I think it's a part of me that I just release to God and, and let it happen.

Most of the nurses reported a strong sense of personal spiritual exploration and spiritual openness as a result of their experiences. Several reported that they share their faith with their patients in many ways. Three nurses described themselves as open to experiences with guardian angels and expressed newfound beliefs in reincarnation, ideas that they had not previously considered seriously.

Practice Domain. The practice domain reflected the beliefs of the nurses regarding the ways in which they experienced emotional growth as a result of their experiences, and how this growth influenced their practice. All the nurses reported that they were more understanding of people in general, and of patients and families specifically. Nurses reported that they were more compassionate and sensitive to their patients' emotional needs, including the patients' need to talk about their experiences. Nurses reported that they felt more comfortable during a crisis, and they were more comfortable talking with patients and their families about death. They also mentioned that they felt more comfortable talking to the patient during a code. Nurses also reported that they were also more sensitive to what is said in the presence of their unconscious patients, including cardiac arrest victims.

Nurses were asked what advice they would give to other nurses and health professionals in general regarding patients who have experienced NDEs. The nurses as a whole felt that it was important to accept the NDE as reality for the patient, whether or not the nurse truly believed it. They agreed that the nurse's role was to not judge the patient's values, beliefs, and feelings but to accept them as important to the patient. The nurses also reported that they felt strongly that it was important to realize that patients may be able to hear and see events around them, even though they otherwise appear unconscious. The nurses who related the stories of NDEs among their patients were clearly shaken by them and made special efforts in their own practice to remember that patients may be more aware than they outwardly appear.

\section{Discussion}

This study was designed to explore the nature and meaning of the NDE from both patients' and nurses' perspectives. The data reported by nurses added important details to the stories of patients, which, up until now, have gone uncorroborated. In this way, the results reflect 
the consistency of accounts across and within the patient and nurse groups. In this study, efforts were made to corroborate the sequence of events of the near-death event in the medical record, and nurses have corroborated some of the features experienced by patients.

The sample and sampling selection process in this study overcame the limitations of previous work in several ways. First, the inclusion criteria were specific, including only those who experienced a period of unconsciousness and some memory of that unconsciousness. Second, eight hospitals serving diverse populations were used to add a wide variety to the sample based on ethnicity, gender, and other factors. Third, we were able to verify the state of nearness to death with the medical record and/or with the patients' nurses. Finally, the research questions included the nurses' experiences in order to provide a more comprehensive view of the subject.

The findings reported in this study regarding the features of NDEs parallel those reported in the literature, with the exception of panoramic memory or life review, which was not reported by any patients in this study. The reason for this is unclear; however, patients were not specifically asked about any specific features of the NDE. Had they been asked specific questions, the results might have been different. The findings regarding the meaning of the NDE also corroborate those previously reported in the literature. The findings reported by the patients in this study were similar to those in a phenomenological study of meaning of the NDE conducted by Jann Devereaux (1995). In her study of 10 patients, Devereaux found 5 themes of meaning: a knowing of the Light/Source/God, absence of fear related to death and dying, enhanced relationship with self and others, a clarified purpose for living life, and an expansion of intuitive and psychic abilities. Devereaux included in her study patients who had their NDE at least one year prior to interview and who believed that the NDE had meaning in his or her life.

Our study differed methodologically from Devereaux's in two regards. First, both patients and nurses were recruited in order to capture the nature and meaning of the NDE from both perspectives. Second, Devereaux recruited patients who had an NDE one or more years prior to interview, so the more long-term effects were addressed, whereas we interviewed six patients within one month after their NDE and others up to two years after the event in order to capture the process of responding to an NDE. Yet, despite these methodological differences, there were similar findings of the long-term meaning to the subjects in both studies. 
The explanatory models of the patients' and nurses' experiences illustrate the impact of the NDE on their respective lives. The patients reported frustration as they tried to find a meaning for the NDE. Their feelings manifested in confusion, depression, and feelings of fear that they may be, or others may see them as, crazy. As they resolved these feelings by talking about their experiences with interested and nonjudgmental others, they came to believe that they had received a special gift and saw it as an awakening into a new way of looking at the world. Nurses, too, struggled to explain their experiences in terms of the familiar scientific model. As they realized that their experiences fell outside of the norm, they too, developed a new way of looking at the world.

\section{Spiritual Distress}

The nursing diagnosis of spiritual distress seems an appropriate label for the existential frustration the NDE produced in patients. Spiritual distress is defined as "disruption in the life principle that pervades a person's entire being and that integrates and transcends one's biological and psychosocial nature" (Kim, McFarland, and McLane, 1991, p. 63). Larry Renetzky (1978, p. 215) defined the human spiritual dimension as the need for meaning and purpose in life, the need for hope, and the need for belief in the self, others, and a power beyond the self. The NDE. was the event that disrupted the person's view of the world. It was also the turning point that led to an awakening of the spirit, which in turn created in the person a different outlook on life.

Traditionally, nurses have not been accustomed to addressing the spiritual concerns of patients and have been quick to refer them to chaplains or ministers to meet these concerns (Ross, 1994). However, Carole Piles (1990) pointed out that the chaplain should not automatically be called when the patient mentions religious or spiritual concerns, because, to many patients, clergy represent holiness, and they may not necessarily be having holy feelings-especially if they are dealing with guilt or confusion. The literature shows that nurses are likely to be approached first with these spiritual concerns and must be comfortable enough to address such concerns with dignity, respect, and compassion.

\section{Limitations of This Study}

While this study was designed to overcome the shortcomings of previous studies in this field, there still remained some limitations, including 
sample size and method of recruitment. These limitations were primarily issues of generalizability.

A sample size of 12 patients was a limitation in terms of quantitative data analysis. Because of this, reliabilities on the structured instrument were relatively low. However, the depth of data collected on these 12 patients and 19 nurses resulted in more than 900 pages of transcripts and hundreds more of coded passages.

Another limitation was the method of recruitment of subjects. Participants were self-selected volunteers who met the inclusion criteria. For patients, the primary criterion was that they had memory of a period of unconsciousness. One method to overcome this limitation was to review the medical record to validate the period of unconsciousness. Unfortunately, it was possible to review the medical records of only seven subjects. The remainder of them were unavailable for inspection, most often because the patients had their experiences in hospitals that were not involved in the study, two of which were out of state. Another recruitment issue was that of time span since the NDE. We initially intended to interview all patients within days of the NDE and conduct a second interview after four to six months in order to capture the dynamics of the aftermath of the NDE. After 18 months of data collection with only four patients recruited, we decided to increase the time frame to up to two years after the NDE.

Another limitation was that there was no mechanism to provide patient-nurse pairs in the sample. In this study, we were able to include only one patient-nurse pair. We might learn more about the nature of NDEs and be able to validate the total experience if there was an effort to include patient-nurse pairs.

A final limitation was one of sample bias. It is interesting to note that several of the nurse participants also had personally experienced an NDE at some point in the past. In fact, two of the original nurse participants experienced an NDE within two years of the interview, and were therefore included with the patient sample; and four other nurses in the nurse sample experienced an NDE longer that two years prior to the interview, and were kept in the nurse sample. This may be considered a limitation in that, since they may have been "sensitized" to the NDE, their responses may not have reflected the general population of nurses.

\section{Implications for Practice}

The findings from this study also supported the nursing literature on NDEs. Two nurse researchers, Janet Schwaninger (personal 
communication, January 1993) and Margaret Garrison (1989), found that patients needed their stories of NDEs to be taken seriously, and that the most helpful intervention by health professionals was giving patients the opportunity to talk about the NDE in a nonjudgmental atmosphere. The patients in this sample also expressed the importance of caregivers being nonjudgmental. They wanted health professionals to realize that patients initially may be confused about the experience. They also emphasized that it is especially important not to minimize the NDE by labeling it as an hallucination.

The NDE was a meaningful experience for both the patient and the nurse. Nurses must realize that patients may be aware of what is going on around them, even though they may give the appearance of unconsciousness. Unconsciousness did not necessarily indicate lack of awareness; in fact, patients reported that the NDE produced acute awareness. While patients appeared unaware of events outside of themselves, they were often acutely aware of events-more aware than if they had been conscious.

Several patients in this sample were initially rather hesitant to share their experience with the interviewer, for fear of being though of as crazy. They expressed the desire to talk about the experience with others, and stated that talking about it helped to put it into perspective and to reassure them. Patients were sensitive to having their experience minimized and reported being reluctant to discuss it with people who minimized it. Nurses and physicians can capitalize on this opportunity by asking all of their patients who have experienced a period of unconsciousness whether they have some memories of it. In speaking with patients, health professionals should remember that to refer to the NDE as a dream, an hallucination, or the result of certain drugs is to minimize it for the patient, and may make them less willing to talk about it. However, patients may say to the professional that they have had a "weird dream,"which should be a clue that they may have had an NDE. Patients will often admit to a dream in order to get an idea of how the nurse or physician will respond. When patients know that they have an interested listener, they may then confess that they know that their experience was very different from a dream, yet they are unsure how to convey that to the listener.

Nurses, physicians, and other health professionals must be sensitive to the beliefs of the patients and allow them to come to an understanding of the experience that the patient is comfortable with. Many patients believe that they have seen a glimpse of what is to come; health professionals must respect this belief and allow their patients to express their 
feelings about it. Whether or not we may share their interpretation of their experience, we must respect their feelings and beliefs.

This study suggests that the NDE produced a significant spiritual awakening in both patients and nurses, and it provided a unique message for both. The subject of NDEs has interested not only nurses, but the general public as well. Topics related to spirituality, transcendentalism, and Eastern thought are new to the Western world. New ideas that could potentially transform accepted beliefs about what we know as reality often are met with skepticism. The same is true of the NDE. It is only by continued repeatable and verifiable studies that we will come to realize that the boundaries between natural phenomena and "supernatural" are sometimes blurred.

Nurses and other health professionals are educated in the medical model that promotes scientific thought as the ideal. We have been trained to correct patients when they report seeing things or hearing things that appear to be a figment of their imagination. The findings from this study show that the optimal or therapeutic response for these patients is not correction of this "faulty" view. Patients reported that they wanted and needed confirmation of their experience by professionals. In addition, the experiences of the nurses were outside of their knowledge and expertise as well. They were hesitant to discuss their experiences because they feared they would be met with the same skepticism that their patients were met with-and this was not acceptable behavior or thinking for a professional person. As this study shows, there are scientifically unexplainable phenomena that do occur to patients who are critically ill. The NDE was a meaningful experience for both patients and nurses. It is important that we recognize that the NDE can be an awakening to a new avenue of spiritual exploration for both patients and nurses alike.

\section{References}

Atwater, P. M. H. (1988).Coming back to life: The after-effects of the near-death experience. New York, NY: Dodd, Mead.

Bauer, M. (1985). Near-death experience and attitude change. Anabiosis: The Journal of Near-Death Studies, 5(1), 39-47.

Blackmore, S. J. (1988). Visions from the dying brain. New Scientist, 118(1611), 43-46.

Blackmore, S. J. (1991). Near-death experiences: In or out of the body? Skeptical Inquirer, $16,34-45$.

Bush, N. (1994). The paradox of Jonah: Response to "Solving the riddle of frightening near-death experiences." Journal of Near-Death Studies, 13, 47-54.

Carr, D. B. (1982). Pathophysiology of stress-induced limbic lobe dysfunction: A hypothesis for NDEs. Anabiosis: The Journal of Near-Death Studies, 2, 75-89. 
Devereaux, J. (1995). Living life after encountering the light: A phenomenological exploration of the meaning of the near-death experience. Unpublished doctoral dissertation, The Union Institute, Cincinnati, $\mathrm{OH}$.

Emergency Cardiac Care Committee and Subcommittees, American Heart Association. (1992). Guidelines for cardiopulmonary resuscitation and emergency cardiac care. I: Introduction. Journal of the American Medical Association, 268, 2172-2183.

Featherston, R. (1998). Care of sudden cardiac death survivors: The aberrant cardiac patients. Heart and Lung, 17, 242-246.

Garrison, M. (1989). Survivors of cardiac arrest or "arrest-like" events: Recollections and perceptions. Unpublished masters thesis, Yale University, New Haven, CT.

Grey, M. (1985). Return from death: An exploration of the near-death experience. London, England: Arkana.

Greyson, B. (1983). The near-death experience scale: Construction, reliability, and validity. Journal of Nervous and Mental Disease, 171, 369-375.

Greyson, B. (1985). A typology of near-death experiences. American Journal of Psychiatry, $140,967-969$.

Greyson, B., and Bush, N. E. (1992). Distressing near-death experiences. Psychiatry, 55, 95-110.

Greyson, B., and Stevenson, I. (1980). The phenomenology of near-death experiences. American Journal of Psychiatry, 137, 1193-1196.

Guralnik, D. (Ed.). (1980).Webster's new world dictionary of the American language. (2nd college ed.). New York, NY: Simon and Schuster.

Haase, J. E., Britt, T., Coward, D. D., Leidy, N. K., and Penn, P. E. (1992). Simultaneous concept analysis of spiritual perspective, hope, acceptance, and self-transcendence. Image: Journal of Nursing Scholarship, 24, 141-147.

James, D. (1994). Factors in the nursing environment which promote disclosure of neardeath experiences. Unpublished masters thesis, Incarnate Word College, San Antonio, TX.

Jansen, K. L. R. (1990). Neuroscience and the near-death experience: Roles for the NMDAPCP receptor, the sigma receptor and the endopsychosins. Medical Hypotheses, 31, 25-29.

Kim, M. J., McFarland, G. K., and McLane, A. M. (1991). Pocket guide to nursing diagnosis. St. Louis, MO: Mosby Year Book.

Lincoln, Y., and Guba, E. (1985). Naturalistic inquiry. Newbury Park, CA: Sage Publications.

Moody, R. A. (1975). Life after life. Covington, GA: Mockingbird Books.

Morris, L., and Fachet, K. (1992). Incorporating critical care monitoring tools in your QA program. Critical Care Nurse, 12(5), 87-96.

Morse, M. L., Castillo, P., Venecia, D., Milstein, J., and Tyler, D. C. (1986). Childhood near-death experiences. American Journal of Diseases in Children, 140, 11101114.

Noyes, R. (1980). Attitude change following near-death experiences. Psychiatry, 43, 234242.

Noyes, R., and Slymen, D. (1978-79). The subjective response to life-threatening danger. Omega, 9, 313-321.

Pasricha, S., and Stevenson, I. (1986). Near-death experiences in India: A preliminary report. Journal of Nervous and Mental Disease, 174, 165-170.

Piles, C. (1990). Providing spiritual care. Nurse Educator, 15(1), 36-41.

Rawlings, M. (1978). Beyond death's door. Nashville, TN: Thomas Nelson.

Rawlings, M. (1993). To hell and back: Life after death-Startling new evidence. Nashville, TN: Thomas Nelson.

Renetzky, L. (1978). The fourth dimension: Applications to the social services. In D. O. Moberg (Ed.). Spiritual well-being: Sociological perspectives (pp. 138-217). Washington, DC: University Press of America. 
Ring, K. (1980). Life at death: A scientific investigation of the near-death experience. New York, NY: Coward, McCann and Geoghegan.

Ring, K. (1984).Heading toward omega: In search of the meaning of the near-death experience. New York, NY: William Morrow.

Ring, K., and Valarino, E. E. (1998). Lessons from the light: What we can learn from the near-death experience. New York, NY: Plenum/Insight.

Ritchie, G., and Sherrill, E. (1978). Return from tomorrow. Waco, TX: Chosen Books.

Ross, L. (1994). Spiritual care: The nurse's role. Nursing Standard, 8(29), 33-37.

Twemlow, S. W., and Gabbard, G. O. (1984-85). The influence of demographic/psychological factors and preexisting conditions on the near-death experience. Omega, 15, 223-235. 